\title{
Asesmen Kualitas Lingkungan di PSIKLH Kawasan Puspiptek Serpong- Tangerang Selatan
}

\section{Environmental Quality Assessment at PSIKLH in the Serpong-South Tangerang Puspiptek Area}

\author{
Rita Mukhtar ${ }^{1}$, Ernawita Nazir ${ }^{1}$, Bambang Hindratmo ${ }^{1}$, Ricky Nelson ${ }^{1}$, \\ Oktaria Diah Pitalokasari', Yunesfi Syofyan ${ }^{1}$, Siti Masitoh ${ }^{1}$, dan Amallia Dainah ${ }^{2}$ \\ 'Pusat Standardisasi Instrumen Kualitas Lingkungan Hidup (PSIKLH)-KLHK, Kawasan PUSPIPTEK Gedung \\ 210, Serpong - Tangerang Selatan 15310 \\ ${ }^{2}$ Program Studi Kimia Fakultas Sains dan Teknologi, Universitas Islam Negeri Syarif Hidayatullah Jakarta, \\ Jl. Ir. H. Djuanda No. 95, Ciputat - Tangerang Selatan 15412 \\ E-mail: ritaiim@yahoo.com
}

Diterima 28 Oktober 2021, direvisi 12 November 2021, disetujui 19 November 2021

\begin{abstract}
ABSTRAK
Asesmen Kualitas Lingkungan di PSIKLH Kawasan Puspiptek Serpong-Tangerang Selatan. Pusat Standardisasi Instrumen Kualitas Lingkungan Hidup (PSIKLH) merupakan salah satu instansi yang berada di kawasan Puspiptek dengan kegiatan laboratorium pengujian dan laboratorium kalibrasi. Asesmen kualitas lingkungan di PSIKLH dilakukan mencakup kualitas udara ambien, udara emisi, air, tanah, dan sedimen periode 2018-2020. Pengambilan contoh uji dan analisis parameter mengacu pada metode Standar Nasional Indonesia dan metode lainnya yang sudah baku. Hasil asesmen dibandingkan dengan baku mutu masing-masing parameter sesuai peraturan yang ada. Konsentrasi TSP, $\mathrm{PM}_{10}$, $\mathrm{PM}_{2,5}, \mathrm{SO}_{2}, \mathrm{NO}_{2}$, dan $\mathrm{O}_{3}$ di PSIKLH hampir semua berada di bawah baku mutu berdasarkan Peraturan Pemerintah No.41/1999 tentang Pengendalian Pencemaran Udara, namun ada 8 dari 28 data $\mathrm{PM}_{2,5}$ berada di atas baku mutu. Konsentrasi $\mathrm{H}_{2} \mathrm{~S}$ dan $\mathrm{NH}_{3}$ berada di bawah baku mutu sesuai Keputusan Menteri Negara Lingkungan Hidup No. 50/1996 tentang Baku Tingkat Kebauan. Pada asesmen tahun 2018, konsentrasi partikulat, $\mathrm{SO}_{2}$, NOx, dan $\mathrm{CO}$ pada generator berada di bawah baku mutu berdasarkan PermenLH No. 21/2008. Setelah peraturan baru PP No.15/2019 dikeluarkan, konsentrasi CO dan NOx telah melebihi baku mutu tersebut. PSIKLH mengirimkan limbah bahan berbahaya dan beracun (B3) ke pihak eksternal untuk dapat diolah, sedangkan untuk limbah cair domestik dilakukan pengolahan dan pengujian sebelum dibuang ke lingkungan. Kualitas limbah domestik parameter pH, BOD, COD, minyak lemak, TSS dan amoniak berada di bawah baku mutu berdasarkan Permen LHK No.68/2016 tentang Baku Mutu Air Limbah Domestik. Konsentrasi tanah di PSIKLH dan sedimen sungai di sekitar Kawasan Puspiptek berada di bawah baku mutu berdasarkan Canadian Soil Quality Guidelines for the Protection of Environmental and Human Health dan juga Canadian Sediment Quality Guidelines for the Protection of Aquatic Life in Freshwater. Pemantauan rutin dan komprehensif lingkungan kawasan perlu dilakukan untuk mengetahui sumber pencemar yang potensial mencemari kawasan Puspiptek sehingga dampak pencemaran dapat diatasi.
\end{abstract}

Keywords: kualitas, lingkungan, udara, ambien, emisi, limbah, domestik, PSIKLH, Puspiptek.

\section{ABSTRACT}

Environmental Quality Assessment at PSIKLH Puspiptek Serpong-South Tangerang. Center for Standardization of Environmental Quality Instrument (PSIKLH) is one of the agencies located in Puspiptek area with testing laboratory and calibration laboratory activities. The environmental quality assessment at PSIKLH is carried out covering the quality of ambient air, emission air, water, soil, and 
sediment for 2018-2020 period. Sampling and analysis of all parameters are referred to the Indonesian National Standard method and other standard methods. The assessment results are compared with the quality standards of each parameter according to existed regulations. The concentrations of TSP, PM $10^{\circ}$ $\mathrm{PM}_{2.5}, \mathrm{SO}_{2}, \mathrm{NO}_{2}$, and $\mathrm{O}_{3}$ in PSIKLH were almost all below quality standard based on Government Regulation No. 41/1999 concerning Air Pollution Control, however, there were 8 of 28 PM $_{2.5}$ data were above the quality standard. $\mathrm{H}_{2} \mathrm{~S}$ and $\mathrm{NH}_{3}$ level were below the quality standard according to Decree of the State Minister of Environment No. 50/1996 concerning Odor Level Standards. For assessment in 2018 , the level of particulate, $\mathrm{SO}_{2}, \mathrm{NOx}$, and CO in generator were below the quality standard based on Permen LH No. 21/2008. After new regulation, namely PP No. 15 of 2019 is issued, the concentration of $C O$ and NOx is known to have exceeded the quality standard. PSIKLH sends hazardous and toxic waste (B3) to third parties for treatment, while domestic liquid waste is processed and analyzed prior to release to the environment. The domestic waste quality of $p H, B O D, C O D$, fatty oil, TSS and ammonia parameters were below the quality standard, based on the Minister of Environment and Forestry Regulation No. 68/2016 concerning Domestic Wastewater Quality Standards. Soil concentrations in PSIKLH and river sediments around the Puspiptek area are below the quality standard based on Canadian Soil Quality Guidelines for the Protection of Environmental and Human Health, and also Canadian Sediment Quality Guidelines for the Protection of Aquatic Life in Freshwater. Routine and comprehensive environmental monitoring needs to be carried out to identify the potential sources of pollutants contaminating the Puspiptek area, so that the impact of pollution could be overcome.

Kata kunci: environmental quality, ambient air, domestic waste, PSIKLH, Puspiptek area.

\section{Pendahuluan}

PSIKLH berada di bawah Badan Standardisasi Instrumen Lingkungan Hidup dan Kehutanan (BSILHK) yang ditetapkan berdasarkan Peraturan Menteri Lingkungan Hidup dan Kehutanan No. 15 Tahun 2021 tentang Organisasi dan Tata Kerja Kementerian Lingkungan Hidup dan Kehutanan. PSIKLH berlokasi di Kawasan Perkantoran Pusat Penelitian Ilmu Pengetahuan dan Teknologi (PUSPIPTEK) J1. Raya Puspiptek Serpong-Tangerang Selatan, Banten (Gambar 1). Tupoksi PSIKLH adalah melaksanakan penyusunan kebijakan teknis dan pelaksanaan perencanaan, perumusan, pengembangan, dan penilaian kesesuaian standar instrumen kualitas lingkungan hidup, pelaksanaan penyelenggaraan sistem dan rujukan standar instrumen pengelolaan laboratorium lingkungan.

PSIKLH mempunyai enam laboratorium pengujian dan satu laboratorium kalibrasi yang sudah terakreditasi KAN. Laboratorium pengujian terdiri atas laboratorium udara, laboratorium air dan limbah cair, laboratorium biologi, laboratorium tanah dan limbah padat, laboratorium kebisingan dan getaran, dan laboratorium toksik. Pada tahun 2020, PSIKLH membangun laboratorium merkuri dan metrologi lingkungan yang berlokasi di area Pusat Teknologi Lingkungan (Geostech) Badan Pengkajian dan Penerapan Teknologi, Kawasan Puspiptek dengan titik koordinat S.6²1'34.6" - E.106²40'19.3".

Kegiatan di laboratorium dapat menjadi sumber limbah Bahan Berbahaya dan Beracun (B3) jika tidak dikelola dengan baik. Limbah laboratorium berasal dari sisa pengujian, bahan kimia kadaluwarsa, limbah tisu, glass wool dan bahan lain yang digunakan selama pengujian. Limbahlimbah ini harus dikelola dengan baik sebelum dibuang ke lingkungan.

Undang-Undang No.32 Tahun 2009 tentang Perlindungan dan Pengelolaan Lingkungan menyebutkan bahwa Bahan 


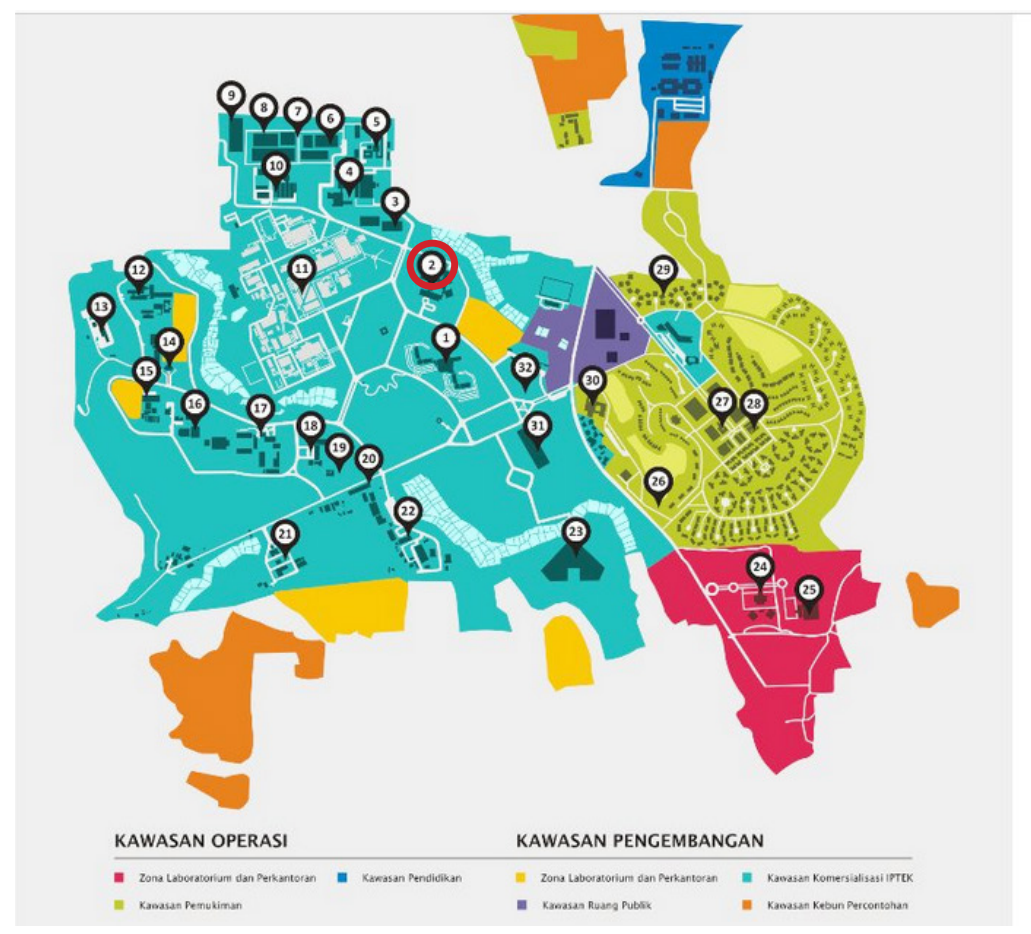

\section{PUSPIPTEK}

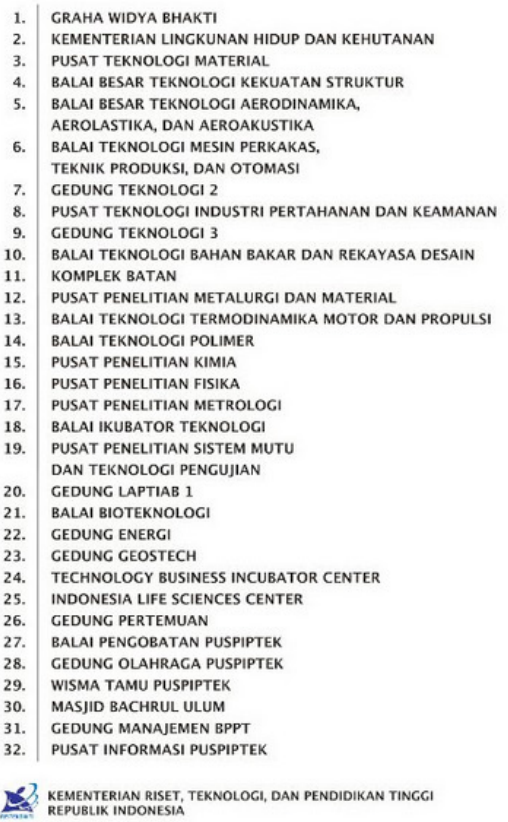

Sumber: https://puspiptek.brin.go.id/peta-kawasan/

Gambar 1. Lokasi Laboratorium PSIKLH -KLHK di dalam Kawasan Puspiptek.

Berbahaya dan Beracun adalah zat, energi, dan/atau komponen lain yang karena sifat, konsentrasi, dan/atau jumlahnya, baik secara langsung maupun tidak langsung, dapat mencemarkan dan/atau membahayakan lingkungan hidup, kesehatan, serta kelangsungan hidup manusia dan makhluk hidup lain. Tujuan kegiatan ini adalah untuk melakukan pemantauan terhadap kualitas udara ambien, udara emisi, air, tanah dan sedimen di lingkungan PSIKLH.

Pencemaran udara terjadi jika udara di atmosfer dicampuri dengan suatu zat yang dapat mempengaruhi dan mengganggu organisme hidup (Sastrawijaya, 1991). Menurut Soedomo, (2001), pencemaran udara terjadi karena adanya perubahan lingkungan udara akibat dari masuknya zat pencemar ke udara dalam bentuk gas-gas dan partikel kecil ke dalam udara. Kegiatan asesmen pencemaran udara di kawasan ini meliputi pengujian udara ambien dan udara emisi di fasilitas genset PSIKLH.

Menurut Peraturan Pemerintah Republik Indonesia Nomor 32 tahun 2009 menyebutkan bahwa yang termasuk dalam kategori Bahan Beracun dan Berbahaya (B3) adalah zat, energi, dan/atau komponen lainnya karena sifat dan konsentrasi tertentu baik secara langsung maupun tidak langsung dapat mencemarkan dan/atau merusak lingkungan hidup serta membahayakan kesehatan dan kelangsungan hidup manusia dan mahluk hidup lainnya. Limbah laboratorium termasuk dalam kategori limbah B3. Menurut Brawijaya (2015), yang termasuk dalam limbah B3 adalah bahan mudah meledak (eksplosive), mudah terbakar (flammable) seperti pelarut organik dan bahan bakar, reaktif seperti oksidator, korosif, infeksius, irritan dan beracun seperti $\mathrm{HCN}$.

Pengelolaan limbah B3 merupakan sebuah kegiatan yang mencakup pengumpulan, penyimpanan, pengangkutan serta pengolahan (Sidik \& Damanhuri, 2012). PSIKLH sudah melakukan pengelolaan terhadap limbah laboratoriumnya. Limbah sisa pengujian, bahan kimia kadaluarsa, dan limbah padat (tisu, glass wool, kertas saring 
dan lain lain) ditampung dalam kontainer terpisah sesuai cara penyimpanan limbah B3 pada fasilitas penyimpanan limbah B3 Lampiran VII, PermenLHK No. 6 Tahun 2021 tentang Tata Cara dan Persyaratan Pengelolaan Limbah Bahan Berbahaya dan Beracun. Limbah B3 yang sudah ditempatkan pada kontainernya kemudian diserahkan pada pihak lain (PPLI) untuk diolah, sehingga limbah cair yang diolah di PSIKLH hanya berasal dari limbah domestik.

\section{Metodologi}

Asesmen kualitas lingkungan di PSIKLH dilakukan mencakup kualitas udara ambien, udara emisi, air, tanah, dan sedimen pada periode 2018-2020. Lokasi kegiatan di PSIKLH Gedung 210 kawasan Puspiptek Serpong Tangerang Selatan, Provinsi Banten, dengan titik pengambilan contoh uji disajikan pada Tabel 1 .

Matrik, parameter dan acuan yang digunakan disajikan pada Tabel 2.

Tabel 1. Titik Pengambilan Contoh Uji

\begin{tabular}{|c|c|c|}
\hline Matrik & GPS & Keterangan \\
\hline Udara ambien & S.06²0' 59.85”- E. $106^{\circ} 40^{\prime} 5.57^{\prime \prime}$ & lapangan bagian tengah kantor PSIKLH \\
\hline Udara emisi & S.06²0' $59.85^{\prime \prime}$ - E. $106^{\circ} 40^{\prime} 5.57^{\prime \prime}$ & \\
\hline Limbah cair & S.06²0' 59.85”- E. $106^{\circ} 40^{\prime} 5.57^{\prime \prime}$ & outlet limbah domestik PSIKLH \\
\hline Air sungai & 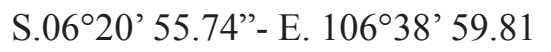 & di sekitar kawasan Puspiptek \\
\hline Sedimen sungai & S.06²0' 55.74’'- E. $106^{\circ} 38^{\prime} 59.81$ & di sekitar kawasan Puspiptek \\
\hline Tanah & S.06 $20^{\circ}$ '59.85"- E. $106^{\circ} 40^{\prime} 5.57^{\prime \prime}$ & di dekat outlet PSIKLH \\
\hline
\end{tabular}

Tabel 2. Matrik, Parameter dan Metode Acuan yang Digunakan

\begin{tabular}{|c|c|c|}
\hline Matrik & Parameter & Metode acuan \\
\hline Udara ambien: & $\begin{array}{l}\text { Partikel debu } \leq 2,5 \mu \mathrm{m},\left(\mathrm{PM}_{2,5}\right) \\
\text { Partikel debu } \leq 10 \mu \mathrm{m},\left(\mathrm{PM}_{10}\right) \\
\text { Partikulat debu }<100 \mu \mathrm{m},(\mathrm{TSP}) \\
\text { Nitrogen Dioksida, }\left(\mathrm{NO}_{2}\right) \\
\text { Sulfur Dioksida, }\left(\mathrm{SO}_{2}\right) \\
\text { Ozon, }\left(\mathrm{O}_{3}\right)\end{array}$ & $\begin{array}{l}\text { SNI 7119.15-2016 } \\
\text { SNI 7119.14-2016 } \\
\text { SNI 7119.3-2017 } \\
\text { SNI 7119.2-2017 } \\
\text { SNI 7119.7-2017 } \\
\text { SNI 7119.8-2017 } \\
\end{array}$ \\
\hline Kebauan: & $\begin{array}{l}\text { Amoniak, }\left(\mathrm{NH}_{3}\right) \\
\text { Hidrogen Sulfida, }\left(\mathrm{H}_{2} \mathrm{~S}\right)\end{array}$ & $\begin{array}{l}\text { SNI 19-7119.1-2005 } \\
\text { MASA Method 701:1988 }\end{array}$ \\
\hline Udara emisi : & $\begin{array}{l}\text { Sulfur Dioksida, }\left(\mathrm{SO}_{2}\right) \\
\text { Oksida-oksida Nitrogen, }\left(\mathrm{NO}_{v}\right)\end{array}$ & $\begin{array}{l}\text { SNI 19. 7117.18- } 2009 \\
\text { SNI 19. 7117.5- } 2005\end{array}$ \\
\hline Limbah cair do & $\begin{array}{l}\text { nestik: } \\
\text { pH, } \\
\text { temperatur } \\
\text { Daya Hantar Listrik (DHL) } \\
\text { Total Dissolved Solid, (TDS) } \\
\text { Biochemical Oxygen Demand (BOD }) \\
\text { Chemical Oxygen Demand, (COD) } \\
\text { Total Suspended Solid, (TSS) } \\
\text { Minyak dan lemak } \\
\text { Salinitas }\end{array}$ & $\begin{array}{l}\text { SNI 6989.11-2019 } \\
\text { APHA 2550-2017 } \\
\text { SNI 06-6989.11-2004 } \\
\text { SNI 06-6989.3-2019 } \\
\text { JIS K 0102 -21-2008 } \\
\text { SNI 6989.2-2009 } \\
\text { SNI 06-6989.3-2019 } \\
\text { APHA 5520 B - } 2017 \\
\text { Electrical Conductivity }\end{array}$ \\
\hline Tanah dan Sed & $\begin{array}{l}\text { nen : } \\
\text { Logam berat } \mathrm{Pb}, \mathrm{Cd}, \mathrm{Zn}, \mathrm{As}, \mathrm{Se} \\
\text { Total merkuri, }(\mathrm{Hg})\end{array}$ & $\begin{array}{l}\text { IK-01/B/PSIKLH } \\
\text { Hg: IK-02/B/PSIKLH }\end{array}$ \\
\hline
\end{tabular}


Pengambilan contoh uji $\mathrm{PM}_{2,5}$, $\mathrm{PM}_{10}$, serta TSP menggunakan alat HVAS dengan waktu pengukuran 24 jam. Nitrogen Dioksida $\left(\mathrm{NO}_{2}\right)$, Ozon $\left(\mathrm{O}_{3}\right)$, Sulfur Dioksida $\left(\mathrm{SO}_{2}\right)$ pengambilan contoh uji menggunakan alat aktif manual dengan waktu pengukuran 1 jam. Baku mutu udara ambien yang digunakan adalah Peraturan Pemerintah No.41/1999 tentang Penyelenggaraan Perlindungan dan Pengelolaan Lingkungan Hidup, karena kegiatan pemantauan ini dilakukan sebelum dikeluarkannya Peraturan Pemerintah No.22 tahun 2021. Pengambilan contoh uji Amoniak $\left(\mathrm{NH}_{3}\right)$ dan Hidrogen Sulfida $\left(\mathrm{H}_{2} \mathrm{~S}\right)$ bertujuan untuk uji kebauan, hasil uji dibandingkan dengan KepMenLH No 50 Tahun 1996 tentang Baku tingkat Kebauan.

Pengukuran kualitas udara emisi dilakukan di cerobong genset PSIKLH dengan output 437 KVA. Hasil analisis dibandingkan dengan baku mutu emisi mesin penunjang produksi untuk pengoperasian mesin dengan pembakaran dalam atau genset sesuai PermenLHK No. 15 tahun 2019 tentang Baku mutu emisi. Di dalam peraturan tersebut menjelaskan baku mutu emisi terdiri atas 2 yaitu BM emisi mesin untuk pengoperasian mesin dengan pembakaran dalam atau genset $\leq 570 \mathrm{~kW}$, dan pembakaran dalam atau genset dengan kapasitas $>570 \mathrm{~kW}$.

Hasil pemantauan parameter outlet limbah domestik PSIKLH dibandingkan dengan baku mutu limbah domestik PermenLHK No.68 Tahun 2016 tentang Baku Mutu Air Limbah Domestik. Pengambilan contoh uji dilakukan di sumur pantau outlet limbah domestik PSIKLH. Pengujian parameter lapang $\mathrm{pH}$, temperatur, DHL, TDS, salinitas dilakukan langsung di lokasi pengambilan contoh uji, sedangkan untuk analisis parameter lainnya dilakukan di laboratorium PSIKLH. Analisis dilakukan segera setelah contoh uji diambil.

Pengambilan contoh uji tanah dilakukan di sekitar outlet PSIKLH pada kedalaman sekitar 20-30 $\mathrm{cm}$ dan di homogenkan. Parameter logam berat $\mathrm{Pb}$, $\mathrm{Cd}, \mathrm{Zn}, \mathrm{As}$, Se dan $\mathrm{Hg}$ di tanah dianalisis sesuai metode yang tercantum pada Tabel 2. Baku mutu logam berat di tanah dan sedimen belum tersedia. Konsentrasi hasil pemantauan dibandingkan dengan Canadian Soil Quality Guidelines for the Protection af Environmental and Human Health dan juga Canadian Sediment Quality Guidelines for the Protection of Aquatic Life in Freshwater.

\section{Hasil dan Pembahasan}

\subsection{Asesmen kualitas udara ambien di PSIKLH}

Pencemaran udara telah menjadi masalah penting yang membutuhkan perhatian serius karena dampaknya terhadap kesehatan manusia dan kualitas lingkungan. Sejumlah besar studi epidemiologi telah menunjukkan bahwa polusi udara menyebabkan efek yang merugikan kesehatan manusia (Santoso et al., 2011). Hasil asesmen kualitas udara ambien di PSIKLH berdasarkan parameter TSP, PM10, dan PM2,5 periode 2018-2020 disajikan pada Gambar 2.

Parameter Total Suspended Particulate (TSP) merupakan partikel dengan ukuran partikel $<100$ mikrometer. Konsentrasi TSP yang diukur selama periode pengukuran berada di bawah baku mutu yaitu $230 \mu \mathrm{g} /$ $\mathrm{m}^{3}$. Mengingat ukuran partikelnya yang lebih besar dibanding $\mathrm{PM}_{10}$ dan $\mathrm{PM}_{2,5}$ maka TSP tidak dapat melayang-layang jauh di udara. Menurut beberapa penelitian, TSP dapat berasal dari kegiatan industri, proses pengolahan, penghancuran, pelembutan bahan organik maupun anorganik seperti batu, arang dan kayu (Sharratt \& Auvermann, 2014). TSP juga dapat berasal dari kegiatan pembakaran, pertambangan, konstruksi, emisi kendaraan bermotor dan industri (Yuwono et al., 2018). TSP juga dapat berasal dari permukaan berbagai jenis tanah di Indonesia dan berasal dari berbagai sumber lain seperti kegiatan pembakaran 


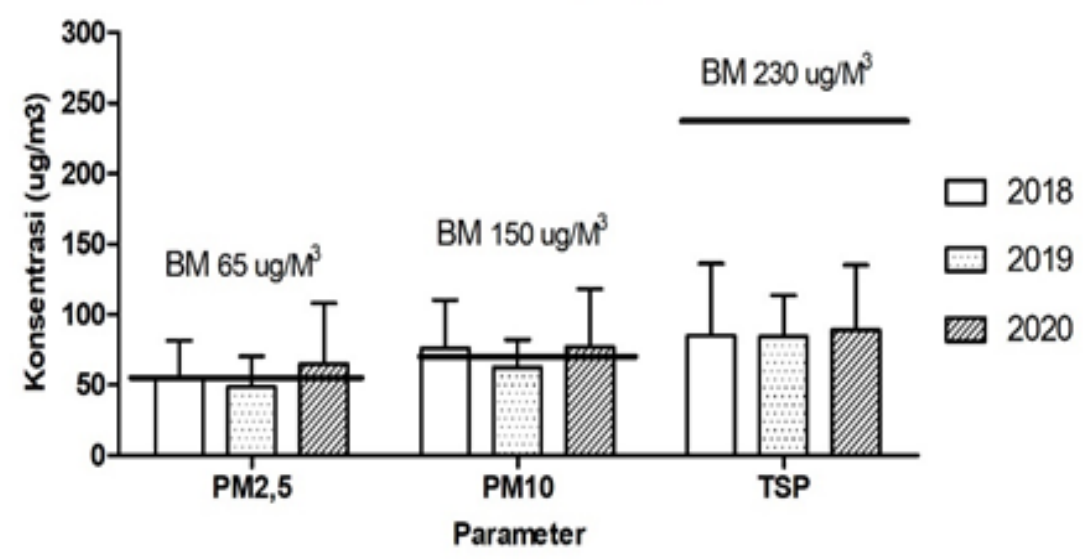

Sumber: Data primer

Gambar 2. Konsentrasi $\mathrm{PM}_{2.5}, \mathrm{PM}_{10}$ dan TSP di PSIKLH

dan non pembakaran pada proses industri, konstruksi, pembukaan lahan, pengolahan tanah, penggundulan hutan dan kendaraan bermotor (Bachtiar \& Sanggar Rani, 2017; Rochmawati, 2014)

Konsentrasi $\mathrm{PM}_{10}$ di PSIKLH juga berada dibawah baku mutu berdasarkan PP 41 tahun 199 yaitu $150 \mu \mathrm{g} / \mathrm{m}^{3}$, namun jika dibandingkan dengan baku mutu yang baru yaitu Peraturan Pemerintah No.22 tahun 2021 tentang Penyelenggaraan Perlindungan dan Pengelolaan Lingkungan Hidup, Lampiran VII, terdapat 9 dari 29 data $\mathrm{PM}_{10}$ yang telah melebihi BM $\mathrm{PM}_{10}$ yaitu $75 \mu \mathrm{g} /$ $\mathrm{m}^{3}$, dengan kisaran data yang melebihi $\mathrm{BM}$ $76-122 \mu \mathrm{g} / \mathrm{m}^{3}$.

Konsentrasi $\mathrm{PM}_{2.5}$ di PSIKLH, terdapat 8 dari 28 data telah melebihi baik BM PP 41 tahun 1999 yaitu $65 \mu \mathrm{g} / \mathrm{m}^{3}$, demikian juga jika dibandingkan dengan baku mutu yang baru PP No.22 tahun 2021, terdapat 10 dari 28 data yang telah melebihi $\mathrm{BM} \mathrm{PM}_{2,5}$ yaitu $55 \mu \mathrm{g} / \mathrm{m}^{3}$. Kisaran data yang melebihi kedua BM tersebut adalah 56-103 $\mu \mathrm{g} / \mathrm{m}^{3}$.

Beberapa potensi sumber pencemar udara $\mathrm{PM}_{2,5}$ dan $\mathrm{PM}_{10}$ berasal dari kegiatan antropogenik seperti emisi kendaraan bermotor, pembakaran biomassa dan pembakaran bahan bakar. $\mathrm{PM}_{2,5}$ maupun $\mathrm{PM}_{10}$ merupakan partikel berukuran kecil yang mampu berpindah dari suatu tempat ke tempat lainnya. Kecepatan angin dapat mempengaruhi konsentrasi $\mathrm{PM}_{2,5}$ dan $\mathrm{PM}_{10}$ di udara. Kecepatan angin tinggi akan mengurangi konsentrasi polutan karena polutan cepat terurai dan konsentrasinya menjadi rendah. $\mathrm{PM}_{2,5}$ terbukti dapat melayang dan melintas batas negara. Hal ini telah dibuktikan oleh PSTNT-BATAN pada kasus kebakaran hutan di Australia yang dapat mencapai Kota Bandung (Mukhtar et.al., 2013).

Pengukuran $\mathrm{PM}_{10}$ dan $\mathrm{PM}_{2,5}$ ini perlu dilakukan secara kontinu, dan diketahui sumber pencetusnya, mengingat dampak $\mathrm{PM}_{2,5}$ ini lebih serius dari ukuran partikel yang lebih besar lainnya. Hal ini disebabkan karena $\mathrm{PM}_{2,5}$ dapat masuk ke bagian tubuh yang lebih dalam seperti paru-paru, jantung dan selanjutnya dapat menyebabkan penyakit pernafasan bahkan dapat menyebabkan kanker jika $\mathrm{PM}_{2,5}$ tersebut membawa zat yang berbahaya dan beracun seperti logam berat $\mathrm{Pb}, \mathrm{As}, \mathrm{Cd}$, dan lain-lainnya.

Konsentrasi parameter gas $\mathrm{O}_{3}, \mathrm{NO}_{2}$, $\mathrm{SO}_{2}$, disajikan pada Tabel 3. sementara untuk gas $\mathrm{H}_{2} \mathrm{~S}$ dan $\mathrm{NH}_{3}$ pada Tabel 4 .

Konsentrasi $\mathrm{O}_{3}, \mathrm{NO}_{2}$, dan $\mathrm{SO}_{2} \mathrm{di}$ PSIKLH periode 2018-2020 masih di bawah baku mutu PP 41 tahun 1999 maupun PP No. 22 tahun 2021 Lampiran VII. Konsentrasi 
Tabel 3. Konsentrasi $\mathrm{O}_{3}, \mathrm{NO}_{2}$, dan $\mathrm{SO}_{2}$ di PSIKLH

\begin{tabular}{|c|c|c|c|c|c|c|c|}
\hline \multirow{2}{*}{ No } & \multirow{2}{*}{ Parameter } & \multirow{2}{*}{ Satuan } & \multicolumn{3}{|c|}{ Hasil } & \multirow{2}{*}{$\begin{array}{l}\text { Baku mutu } \\
\text { PP 41/1999 }\end{array}$} & \multirow{2}{*}{$\begin{array}{l}\text { Baku mutu } \\
\text { PP 22/2021 }\end{array}$} \\
\hline & & & A & $\mathrm{B}$ & $\mathrm{C}$ & & \\
\hline 1 & Oksidan $\left(\mathrm{O}_{3}\right)$ & $\mu \mathrm{g} / \mathrm{m}^{3}$ & 42 & 39 & 22 & 235 & 150 \\
\hline 2 & Nitrogen dioksida $\left(\mathrm{NO}_{2}\right)$ & $\mu \mathrm{g} / \mathrm{m}^{3}$ & 8,8 & 23 & 9,8 & 400 & 200 \\
\hline 3 & Sulfur dioksida $\left(\mathrm{SO}_{2}\right)$ & $\mu \mathrm{g} / \mathrm{m}^{3}$ & 31 & 39 & 20 & 365 & 150 \\
\hline
\end{tabular}

Sumber: data primer, Keterangan waktu sampling: $A=2018, B=2019, C=2020$

Tabel 4. Hasil Uji Kebauan di PSIKLH

\begin{tabular}{|c|c|c|c|c|c|c|}
\hline \multirow{2}{*}{ No } & \multirow{2}{*}{ Parameter } & \multirow{2}{*}{ Satuan } & \multicolumn{3}{|c|}{ Hasil } & \multirow[t]{2}{*}{ Baku mutu } \\
\hline & & & A & B & $\mathrm{C}$ & \\
\hline 1 & Hidrogen sulfida $\left(\mathrm{H}_{2} \mathrm{~S}\right)$ & ppm & 0,0025 & 0,0019 & 0,0015 & 0,02 \\
\hline 2 & Amoniak $\left(\mathrm{NH}_{3}\right)$ & ppm & 0,29 & 0,11 & 0,056 & 2,0 \\
\hline
\end{tabular}

Sumber: data primer, Keterangan waktu sampling: $A=2018, B=2019, C=2020$

$\mathrm{H}_{2} \mathrm{~S}$ dan $\mathrm{NH}_{3}$ juga berada di bawah baku mutu sesuai Keputusan Menteri Negara Lingkungan Hidup No. 50 Tahun 1996 tentang Baku Tingkat Kebauan. Sumber pencemaran gas dan kebauan dapat berasal dari aktivitas alami dan antropogenik di sekitar lokasi sampling, seperti dari kegiatan transportasi, pelepasan gas alam dan kegiatan industri. Mobilitas yang cukup tinggi juga dapat memengaruhi hasil pengukuran parameter gas dan kebauan disekitar lokasi pengambilan sampel Wardhani, (2019). Kegiatan pemantauan harus selalu dilakukan walaupun hasil pengukuran berada di bawah BM.

\subsection{Asesmen kualitas udara emisi di PSIKLH}

Kapasitas genset PSIKLH 437 $\mathrm{kW}$, fasilitas genset biasanya digunakan untuk mendukung kegiatan operasional perkantoran, juga digunakan untuk pelatihan pengujian udara emisi. Hasil pengukuran contoh uji udara emisi genset PSIKLH disajikan pada Tabel 5.

Hasil asesmen udara emisi genset PSIKLH tahun 2018 parameter partikulat, SO2, NOx, dan $\mathrm{CO}$ berada di bawah baku mutu berdasarkan PermenLH No. 21 tahun 2008 tentang Baku Mutu Emisi Sumber Tidak Bergerak Bagi Usaha dan/ atau Kegiatan Pembangkit Tenaga Listrik Termal, Lampiran IVA Baku Mutu emisi Sumber Tidak Bergerak Bagi PLTD, namun setelah keluar PermenLHK No. 15 tahun 2019 tentang baku mutu Pembangkit Listrik Tenaga Termal, maka baku mutu yang digunakan untuk hasil setelah tahun 2019 dan 2020 mengacu pada Lampiran IX

Tabel 5. Konsentrasi Parameter udara emisi Genset di PSIKLH

\begin{tabular}{llccccc}
\hline \multirow{2}{*}{ Parameter } & \multicolumn{1}{c}{ Acuan } & A & B & C & $\begin{array}{c}\text { BM PermenLH } \\
\text { No. 21 th 2008 } \\
\left(\mathrm{mg} / \mathrm{Nm}^{3}\right)\end{array}$ & $\begin{array}{c}\text { BM PermenLHK } \\
\text { No. 15 th 2019 } \\
\left(\mathrm{mg} / \mathrm{Nm}^{3}\right)\end{array}$ \\
\hline Partikulat & SNI 7117.17-2009 & 58 & 125 & 133 & 150 & - \\
SO2 & SNI 7117.18-2009 & 12 & 66 & 93 & 800 & - \\
NOx & SNI 19-7117.5-2005 & 37 & 77 & 1182 & 1000 & 400 \\
CO & SNI 19-7117.10-2005 & 563 & 580 & 1079 & 600 & 500 \\
\hline
\end{tabular}

Keterangan waktu sampling : $\mathrm{A}=2018, \mathrm{~B}=2019, \mathrm{C}=2020$ 
bagian A. Baku Mutu emisi mesin untuk pengoperasian mesin dengan pembakaran dalam atau genset dengan kapasitas $\leq 570$ $\mathrm{kW}$.

Dari hasil asesmen udara emisi tahun 2019, parameter yang melebihi BM berdasarkan PermenLHK No. 15 tahun 2019 adalah $\mathrm{CO}$, sedangkan hasil asesmen udara emisi genset tahun 2020 untuk NOx dan CO juga melebihi baku mutu PermenLHK No. 15 tahun 2019.

Tinggi rendahnya konsentrasi NOx emisi Genset bergantung pada jenis bahan bakar yang digunakannya. Nilai emisi mengalami penurunan jika menggunakan bahan bakar campuran solar biodiesel dibandingkan solar. Bahan bakar solar menghasilkan emisi tinggi karena memiliki kandungan karbon yang tinggi (Firdausy et al., 2020).

Emisi NOx dapat menyebabkan asidifikasi lingkungan dan berdampak buruk terhadap mahluk hidup (Azimi et al., 2018). Udara yang tercemar gas NOx dapat menghasilkan Peroxy Acetil Nitrates (PAN) yang menyebabkan iritasi mata, PAN juga mampu bereaksi dengan senyawa lain dan membentuk kabut fotokimia yang mengganggu lingkungan (Wardhana, 2004).

\subsection{Asesmen kualitas limbah domestik PSIKLH}

Peraturan Menteri Lingkungan Hidup dan Kehutanan No. 68 tahun 2016 tentang baku mutu air limbah domestik, pasal 3 menyatakan bahwa "Setiap usaha/atau kegiatan yang menghasilkan air limbah domestik wajib melakukan pengolahan air limbah domestik yang dihasilkan". PSIKLH telah melakukan pengolahan terhadap air limbah domestik yang dihasilkan sebelum dibuang ke lingkungan. Hasil pemantauan air limbah domestik PSIKLH disajikan pada Tabel 6.

Hasil asesmen limbah domestik PSIKLH parameter $\mathrm{pH}$, BOD, COD, minyak lemak, TSS dan Amoniak semua berada di bawah baku mutu berdasarkan PermenLHK No.68 Tahun 2016 tentang Baku Mutu Air Limbah Domestik. Tidak dilakukan pengukuran pada periode 2020 karena tidak ada limbah cair yang keluar dari outlet.

Parameter $\mathrm{pH}$ pada perairan menggambarkan seberapa besar tingkat keasaman atau kebasaan suatu perairan. Hasil pengukuran $\mathrm{pH}$ air limbah domestik PSIKLH berada pada rentang 6,9-7,9. hal ini menunjukkan bahwa limbah cair domestik PSIKLH masih berada pada batas ambang baku mutu yang ditetapkan. Pentingnya pengukuran nilai $\mathrm{pH}$ dalam suatu badan air, adalah untuk mengetahui seberapa besar kandungan mineral dan polutan dalam air. Nilai $\mathrm{pH}$ juga dapat di jadikan informasi awal baik atau buruknya kualitas suatu perairan. Nilai $\mathrm{pH}$ sangat menentukan aktivitas mikroorganisme perairan (Pamungkas, 2016).

Parameter $\mathrm{BOD}_{5}$ menentukan jumlah oksigen yang dibutuhkan oleh mikroorganisme aerob untuk menguraikan bahan organik dalam air. Hasil pengujian

Tabel 6. Hasil asesmen limbah domestik PSIKLH

\begin{tabular}{|c|c|c|c|c|c|c|c|}
\hline \multirow{2}{*}{ No } & \multirow{2}{*}{ Parameter } & \multirow{2}{*}{ Satuan } & \multirow{2}{*}{ Metode Analisis } & \multirow{2}{*}{ Baku Mutu } & \multicolumn{3}{|c|}{ Hasil Analisis } \\
\hline & & & & & A & B & $\mathrm{C}$ \\
\hline 1 & $\mathrm{pH}$ & - & SNI 6989.11-2019 & $6-9$ & 7,9 & 6,9 & 7,5 \\
\hline 2 & $\mathrm{BOD}_{5}$ & $\mathrm{mg} / \mathrm{L}$ & JIS K 0102-21-2008 & 30 & $<2$ & 4,4 & 2,1 \\
\hline 3 & $\mathrm{COD}^{\circ}$ & $\mathrm{mg} / \mathrm{L}$ & SNI 6989.2-2009 & 100 & 3 & 7,0 & $<2$ \\
\hline 4 & Minyak Lemak & $\mathrm{mg} / \mathrm{L}$ & APHA 5520 B - 2017 & 5 & 2 & $<2$ & $<2$ \\
\hline 5 & TSS & $\mathrm{mg} / \mathrm{L}$ & SNI 06-6989.3-2019 & 30 & - & - & - \\
\hline 6 & Amoniak, $\mathrm{NH}_{3}-\mathrm{N}$ & $\mathrm{mg} / \mathrm{L}$ & SNI 06-6989.30-2005 & 10 & - & - & - \\
\hline
\end{tabular}

Sumber : data primer, keterangan waktu sampling: $\mathrm{A}=$ Agus 2018, $\mathrm{B}=\mathrm{Des} 2018, \mathrm{C}=2019.2020$ tidak ada data 
Kadar BOD ${ }_{5}$ pada Limbah domestik PSIKLH berkisar antara 2-4,4 mg/L. Kadar ini masih di bawah baku mutu yang ditetapkan yaitu sebesar $30 \mathrm{mg} / \mathrm{L}$. Kadar $\mathrm{BOD}_{5}$ dipengaruhi oleh suhu, $\mathrm{pH}$, dan kandungan senyawa organik yang terdapat pada air limbah (Tebbut, 1992).

COD adalah jumlah oksigen yang dibutuhkan untuk mengoksidasi bahan organik secara kimia. Kadar COD yang tinggi dapat memberikan dampak buruk bagi manusia dan lingkungan (Lumaela, Otok, \& Sutikno, 2013). Kadar COD limbah domestik PSIKLH berkisar 2-3 mg/L, nilai ini masih di bawah baku mutu yaitu 100 $\mathrm{mg} / \mathrm{L}$. Semakin tinggi nilai COD dan BOD pada air limbah, semakin buruk kualitas air limbah tersebut.

\subsection{Logam berat di dalam tanah dan sedimen di sungai kecil kawasan Puspiptek}

Konsentrasi logam berat di dalam tanah di sekitar PSIKLH yang diambil secara komposit di beberapa titik di sekitar outlet kantor PSIKLH dan konsentrasi logam berat di sedimen sungai kecil di kawasan Puspiptek disajikan pada Tabel 7.
Baku mutu logam berat dalam tanah dan sedimen di Indonesia belum tersedia, untuk itu konsentrasi logam berat di tanah dibandingkan dengan Canadian Soil Quality Guidelines for the Protection of Environmental and Human Health. Untuk daerah komersial baku mutu $\mathrm{Pb} 260 \mathrm{mg} /$ $\mathrm{kg}, \mathrm{Cd}=22 \mathrm{mg} / \mathrm{kg}, \mathrm{As}=12 \mathrm{mg} / \mathrm{kg}, \mathrm{Zn}=$ $360 \mathrm{mg} / \mathrm{kg}, \mathrm{Se}=2,9 \mathrm{mg} / \mathrm{kg}, \mathrm{Hg}=24 \mathrm{mg} / \mathrm{kg}$. Demikian juga dengan baku mutu sedimen sungai mengacu pada Canadian Sediment Quality Guidlines for the Protection of Aquatic Life dalam freswater. Baku mutu logam berat sedimen dalam freswater adalah $\mathrm{Pb} 35.0 \mathrm{mg} / \mathrm{kg}, \mathrm{Cd}=0,6 \mathrm{mg} / \mathrm{kg}, \mathrm{As}=5,9$ $\mathrm{mg} / \mathrm{kg}, \mathrm{Zn}=123 \mathrm{mg} / \mathrm{kg}, \mathrm{Hg}=0,17 \mathrm{mg} / \mathrm{kg}$.

Hasil pemantauan logam berat di dalam tanah dan sedimen berada di bawah baku mutu. Logam $\mathrm{Pb}$ dan $\mathrm{Zn}$ merupakan logam berat yang teridentifikasi paling besar. Perbandingan logam $\mathrm{Pb}$ dan $\mathrm{Zn}$ di beberapa lokasi di Indonesia berdasarkan literatur dapat dilihat pada Tabel 8 .

Apabila dibandingkan dengan konsentrasi $\mathrm{Pb}$ dan $\mathrm{Zn}$ dalam tanah di Muara Kaliagung Tegal, Teluk Jakarta dan Teluk Ambon, hasil penelitian $\mathrm{Pb}$ dan $\mathrm{Zn}$ di lokasi PSIKLH masih lebih rendah. Hal ini

Tabel 7. Kandungan logam berat dalam tanah dan sedimen

\begin{tabular}{clcccccc}
\hline \multirow{2}{*}{ No } & \multirow{2}{*}{ Lokasi } & \multicolumn{5}{c}{ Parameter/Konsentrasi (mg/Kg) } \\
& & $\mathrm{Pb}$ & $\mathrm{Cd}$ & $\mathrm{Zn}$ & $\mathrm{As}$ & $\mathrm{Se}$ & $\mathrm{Hg}$ \\
\hline 1 & Sedimen di Sungai kecil (kawasan Puspiptek) & 17,8 & $<1$ & 133 & 2 & $<0,1$ & 0,15 \\
2 & Tanah dekat sungai kecil (kawasan Puspiptek) & 16,1 & $<1$ & 54,7 & $<0,2$ & 0,68 & 0,72 \\
3 & Tanah dekat outlet limbah PSIKLH & 17,6 & $<1$ & 120,9 & 0,7 & $<0,7$ & 0,16 \\
\hline
\end{tabular}

Sumber: data primer

Tabel 8. Konsentrasi logam berat sedimen pada beberapa lokasi di Indonesia

\begin{tabular}{lllll}
\hline No & Lokasi & $\mathrm{Pb}(\mathrm{mg} / \mathrm{kg})$ & $\mathrm{Zn}(\mathrm{mg} / \mathrm{kg})$ & Referensi \\
\hline 1 & Banjir Kanal Barat (BKB) & $4,14-13,93$ & $94,11-183,39$ & Maslukah, (2013) \\
2 & Muara Kaligung Tegal & $17,8-31,4$ & $109,2-112,1$ & Rondi et al., (2021) \\
3 & Teluk Jakarta & $20,19-55,68$ & - & Fitroh et al., (2019) \\
4 & Teluk Ambon & $51,3-163$ & $51,3-163$ & Manullang et al., (2017) \\
5 & Pantai Marunda & $3,11-8,5$ & $70,88-119,88$ & $\begin{array}{l}\text { Nurhidayah } \text { et al., } \\
(2020)\end{array}$ \\
\hline
\end{tabular}


menunjukkan bahwa aktivitas antropogenik di lokasi pengambilan sampel lebih rendah dibanding dengan lokasi Muara Kaliagung, Teluk Ambon dan Teluk Jakarta sehingga akumulasi $\mathrm{Pb}$ dan $\mathrm{Zn}$ di daerah tersebut lebih tinggi.

Unsur logam dalam tanah secara alami berasal dari pelapukan batuan. Logam $\mathrm{Hg}$ pada lokasi tanah dekat sungai kecil didapatkan melebihi baku mutu, hal ini dapat memberikan dampak buruk bagi lingkungan, biota sungai dan juga manusia (Komarawidjaja, 2017). Merkuri (Hg) dianggap sebagai logam berat paling beracun di lingkungan. Keracunan merkuri dapat disebut sebagai penyakit pink atau acrodynia (Morais, Costa, Pereira, \& Lourdes, 2012). Merkuri berbahaya karena memiliki kemampuan untuk bereaksi dengan unsur lain dan membentuk merkuri anorganik dan organik. Paparan merkuri anorganik dan organik dapat menyebabkan kerusakan otak dan gagal ginjal serta janin (Alina et al., 2012).

Hasil pengukuran Seng (Zn) dalam sedimen sungai kecil menunjukkan bahwa hasil pengukuran melebihi baku mutu yang telah ditetapkan. Seng merupakan logam berat yang apabila dalam jumlah rendah sangat dibutuhkan oleh tumbuhan dan manusia. Kelebihan $\mathrm{Zn}$ dapat menyebabkan terganggunya unsur hara lain yang terdapat didalam tanah dan menyebabkan terjadinya ketidakseimbangan. Selain bersumber dari limbah industri, logam Zn juga dapat berasal dari penggunaan pupuk disekitar lokasi sampling dan juga berasal secara alami seperti dari pelapukan batuan dan erosi tanah (Patty, Siahaan, \& Maabuat, 2018). Logam berat dalam tanah dapat terserap kejaringan tanaman melalui akar, lalu terdistribusi kebagian tanaman lainnya. Logam berat yang terakumulasi pada jaringan tubuh dan melebihi batas dapat menimbulkan defisiensi atau keracunan hewan maupun manusia.

\section{Simpulan}

Asesmen kualitas lingkungan di PSIKLH menunjukkan bahwa kualitas udara untuk TSP, $\mathrm{PM}_{10}$ dan $\mathrm{PM}_{2,5}$ perlu dilakukan secara rutin, karena dari hasil pemantauan terdapat indikasi $\mathrm{PM}_{10}$ dan $\mathrm{PM}_{2,5}$ melebihi baku mutu di beberapa waktu pengukuran, untuk mengetahui sumber pencemarnya perlu dilakukan karakteristik sumber pencemar. Semakin kecil ukuran partikulat semakin berbahaya terhadap kesehatan, karena dapat masuk ke dalam jaringan tubuh yang paling dalam.

Asesmen kualitas udara emisi genset PSIKLH tahun 2018 parameter partikulat, $\mathrm{SO}_{2}$, NOx dan $\mathrm{CO}$ berada di bawah baku mutu berdasarkan PermenLH No. 21 tahun 2008. Setelah dikeluarkannya peraturan baru yaitu PP No.15 tahun 2019, konsentrasi CO dan NOx diketahui telah melebihi baku mutu tersebut. Hal ini disebabkan karena baku mutu baru memiliki nilai baku mutu lebih ketat dibandingkan dengan peraturan yang lama. Perawatan yang rutin atau penggunaan solar biodiesel dalam operasional genset dapat mengurangi pencemaran udara emisi genset.

Asesmen kualitas air limbah domestik PSIKLH berdasarkan parameter $\mathrm{pH}$, BOD, COD, minyak lemak, TSS dan Amoniak berada di bawah baku mutu berdasarkan PermenLHK No.68 tahun 2016 tentang Baku Mutu Air Limbah Domestik. Demikian juga asesmen kualitas tanah dan sedimen sungai di kawasan Puspiptek, masih di bawah baku mutu yang diacu.

Pemantauan kualitas lingkungan harus terus dilakukan, hal ini untuk mendapatkan data series dan untuk mengetahui peringatan dini jika terjadinya pencemaran agar tindakan pencegahan dapat dilakukan sedini mungkin. Saran dari hasil asesmen ini adalah agar semua instansi yang mempunyai kegiatan laboratorium di kawasan PUSPIPTEK dapat melakukan asesmen kualitas lingkungan 
di sekitarnya, agar kualitas lingkungan di kawasan Puspiptek dapat diketahui dan dijaga kelestarian lingkungannya.

\section{Ucapan Terima Kasih}

Kami mengucapkan terimakasih banyak kepada pengelola Kawasan Puspiptek, kepada Kepala PSIKLH sehingga kami dapat melakukan kegiatan pemantuan ini dengan baik dan lancar. Terimakasih juga diucapkan kepada rekan laboratorium udara, laboratorium air, dan laboratorium tanah dan limbah padat PSIKLH, serta tim editor dan Mitra Bestari yang telah berkontribusi baik tenaga dan pemikirannya dalam penyediaan data sehingga tulisan ini dapat diselesaikan dengan baik.

\section{Kepengarangan}

Penulis pertama melakukan penyusunan tulisan, penulis kedua melakukan verifikasi data, sementara penulis lainnya melakukan sampling, pengujian, pengolahan, dan membantu interpretasi data. Seluruh penulis merupakan suatu kesatuan tim yang tidak terpisahkan yang telah memberikan kontribusi dalam di setiap bagiannya.

\section{Daftar Pustaka}

Alina, M., Azrina, A., Yunus, A. M., Zakiuddin, S. M., Efendi, H. M. I., \& Rizal, R. M. (2012). Heavy metals (mercury, arsenic, cadmium, plumbum) in selected marine $\mathrm{f} \mathrm{sh}$ and shellf sh along the Straits of Malacca. Int Food ResJ, 19, 135-140.

Azimi, M., Feng, F., \& Yang, Y. (2018). Air Pollution Inequality and Its Sources in SO2 and NOx Emissions Among Chinese Province from 2006 to 2015. Sustainability, 10, 367.

Bachtiar, V. S., \& Sanggar Rani, P. S. (2017). Analisis Debu Respirable terhadap Masyarakat di Kawasan Perumahan Sekitar Lokasi Pabrik PT. Semen Padang. Jurnal Dampak, 13, 1.
Cahyono, T. (2017). Penyehatan Udara. Yogyakarta: Penerbit Andi.

Farhani, N., Rachmawati, E., Budiwati, T., Mulyani, T., Sutamihardja, R., \& Lestari, R. (2010). Status Deposisi Asam di Indonesia Tahun 2001-2008. In Pusarpedal KLH. Tangerang: Pusarpedal KLH.

Firdausy, M. A., Mizwar, A., Khair, R. M., Nitha, I., \& Hamatha, N. (2020). Perbandingan Emisi Gas Buang Yang Dihasilkan Pada Penerapan Biodiesel PT Adaro Indonesia. Jukung Jurnal Teknik Lingkungan, 6, 147156.

Fitroh, I. S., Subardjo, P., \& Maslukah, L. (2019). Hubungan Logam Berat $\mathrm{Pb}$ terhadap Fraksi Sedimen dan Bahan Organik di Muara Sungai Tiram, Marunda, Jakarta Utara. Buletin Oseanografi Marina, 8, 61.

Komarawidjaja, W. (2017). Paparan Limbah Cair Industri Mengandung Logam Berat pada Lahan Sawah di Desa Jelegong, Kecamatan Rancaekek, Kabupaten Bandung. Jurnal Teknologi Lingkungan, 18, 173.

Lumaela, A. ., Otok, B. ., \& Sutikno. (2013). Pemodelan Chemical Oxygen Demand (COD) Sungai di Surabaya dengan Metode Mixed Geographically Weighted regression. Jurnal Sains Dan Seni Pomits, 2, 100-105.

Manullang, C. Y., Lestari, -, Tapilatu, Y., \& Arifin, Z. (2017). Assessment of $\mathrm{Fe}, \mathrm{Cu}$, $\mathrm{Zn}, \mathrm{Pb}, \mathrm{Cd} \& \mathrm{Hg}$ in Ambon Bay Surface Sediments. Marine Research in Indonesia, 42, 83-92.

Maslukah, L. (2013). Hubungan antara Konsentrasi Logam Berat $\mathrm{Pb}, \mathrm{Cd}, \mathrm{Cu}, \mathrm{Zn}$ dengan Bahan Organik dan Ukuran Butir dalam Sedimen di Estuari Banjir Kanal Barat, Semarang. Buletin Oseanografi Marina, 2, 55-62.

Morais, S., Costa, F. G. e, Pereira, \& Lourdes, M. de. (2012). Soils and Human Health. In E. C. Brevik \& L. C. Burgess (Eds.), Environmental Health - Emerging Issues and Practice. CRC Press.

Mukhtar, R., Hamonangan Panjaitan, E., Wahyudi, H., Santoso, M., \& Kurniawati, S. (2013). Komponen Kimia PM2,5 dan PM10 di Udara Ambien di SerpongTangerang. Jurnal Ecolab, 7, 1-7. 
Nurhidayah, T., Maslukah, L., Wulandari, S. Y., \& Kurnia, K. (2020). Distribusi Vertikal Logam $\mathrm{Pb}, \mathrm{Zn}, \mathrm{Cr}$ dan Keterkaitannya Terhadap Karbon Organik Sedimen di Pantai Marunda, Jakarta. Buletin Oseanografi Marina, 9, 125-132.

Pamungkas, M. T.O.A.(2016). Studi Pencemaran Limbah Cair dengan Parameter BOD5 dan $\mathrm{pH}$ di Pasar Ikan Tradisional dan Pasar Modern di Kota Semarang. Jurnal Kesehatan Masyarakat, 4.

Patty, J. O., Siahaan, R., \& Maabuat, P. V. (2018). Kehadiran Logam-Logam Berat $(\mathrm{Pb}, \mathrm{Cd}$, $\mathrm{Cu}, \mathrm{Zn}$ ) Pada Air dan Sedimen Sungai Lowatag, Minahasa Tenggara-Sulawesi Utara. Jurnal Bios Logos, 8. https://doi. org/10.35799/jbl.8.1.2018.20592

Pemerintah Republik Indonesia. UndangUndang Republik Indonesia No.32 Tahun 2009 Tentang Perlindungan dan Pengelolaan Lingkungan Hidup. , (2009).

Pemerintah Republik Indonesia. Peraturan Pemerintah Nomor 22 Tahun 2021 tentang Pedoman Perlindungan dan Pengelolaan Lingkungan Hidup., 1 Sekretariat Negara Republik Indonesia (2021).

Rochmawati, N. R. (2014). Pendugaan Bangkitan Konsentrasi Total Suspended Particulate (Tsp) di Udara Ambien dari Permukaan Tanah. Institut Pertanian Bogor.

Rondi, P. A., Maslukah, L., \& Atmodjo, W. (2021). Pola Sebaran Horizontal Logam Berat Timbal $(\mathrm{Pb})$ dan Zeng $(\mathrm{Zn})$ pada Sedimen di perairan Muara Sungai Kaliagung Tegal. Jurnal Kelautan, 14, 11-19.
Santoso, M., Lestiani, D. D., Mukhtar, R., Hamonangan, E., Syafrul, H., Markwitz, A., \& Hopke, P. K. (2011). Preliminary study of the sources of ambient air pollution in Serpong, Indonesia. Atmospheric Pollution Research, 2, 190-196.

Sastrawijaya, A. T. (1991). Pencemaran Lingkungan. Jakarta: Rineka Cipta.

Sharratt, B., \& Auvermann, B. (2014). Dust Pollution from Agriculture. In N. K. Van Alfen (Ed.), Encyclopedia of Agriculture and Food Systems (pp. 487-504). Elsevier.

Sidik, A. A., \& Damanhuri, E. (2012). Studi Pengelolaan Limbah B3 (Bahan Berbahaya dan Beracun) Laboratorium Laboratorium di ITB. Jurnal Tehnik Lingkungan, 18, 12-20.

Soedomo, M. (Moestikahadi). (2001). Pencemaran Udara: Kumpulan Karya Ilmiah. Bandung: Penerbit ITB.

Tebbut, T. (1992). Principles of water Quality Control (4rd edtion) (4rd Editio). Oxford: Pergamon Press.

Wardhana, A. W. (2004). Dampak Pencemaran Lingkungan (edisi revisi) (3rd ed.). Yogyakarta: Andi Offset.

Wardhani, E. (2019). Profil Kualitas Udara Kota Cimahi Provinsi Jawa Barat. Jurnal Rekayasa Hijau, 3, 61-70.

Yuwono, A. S., Fauzan, M., Raup, A. A., \& Buana, E. G. (2018). Comparison of Dustfall and Total Suspended Particulate Generation from Latosol Soil from Padang and Bandar Lampung Municipalities. 13, 16042-16048. 